\title{
Association between the swine production areas and the human population in Pinar del Río province, Cuba
}

Osvaldo Fonseca ${ }^{1}$, Kleber Régis Santoro ${ }^{2}$, Pastor Alfonso ${ }^{1}$, Joel Ayala ${ }^{1}$, María Antonia Abeledo ${ }^{1}$, Octavio Fernández ${ }^{1}$ Yosdany Centelles ${ }^{1}$, Damarys de las Nieves Montano ${ }^{1}$ and María Irian Percedo ${ }^{1}$

1. Epidemiology Group, Department of Microbiology-Epidemiology, National Center for Animal and Plant Health (OIE Collaborating Center for Disaster Risk Reduction in Animal Health), Carretera de Jamaica y Autopista Nacional, San José de las Lajas, CP 32700, Mayabeque, Cuba; 2. Postgraduate Program in Biometrics and Applied Statistics (PPGBEA), Federal Rural University of Pernambuco (UFRPE), Rua Manuel de Medeiros, s/n - Dois Irmãos, Recife, PE 52171-900, Brazil.

Corresponding author: Osvaldo Fonseca, e-mail: osvaldo820601@gmail.com

Co-authors: KRS: kleber.santoro@ufrpe.br, PA: alfonso@censa.edu.cu, JA: ayala@censa.edu.cu, MAA: abeledo@censa.edu.cu, OF: octavio@censa.edu.cu, YC: yosdany@censa.edu.cu, DNM: damarysmv@censa.edu.cu, MIP: percedo@censa.edu.cu

Received: 22-05-2017, Accepted: 24-06-2017, Published online: 18-07-2017

doi: 10.14202/IJOH.2017.36-41 How to cite this article: Fonseca O, Santoro KR, Alfonso P, Ayala J, Abeledo MA, Fernández O, Centelles Y, Montano DN, Percedo MI. Association between the swine production areas and the human population in Pinar del Río province, Cuba. Int J One Health 2017;3:36-41.

\begin{abstract}
Aim: The aim of this study was to demonstrate the association between high human population density and high pig production in the province of Pinar del Río, Cuba.

Materials and Methods: Records on pig movements at the district level in Pinar del Río province from July 2010 to December 2012 were used in the study. A network analysis was carried out considering districts, as nodes, and movements of pigs between them represented the edges. The in-degree parameter was calculated using R 3.1.3 software. Graphical representation of the network was done with Gephi 0.8.2, and ArcGIS 10.2. was used for the spatial analysis to detect clusters by the Getis-Ord Gi* method and visualize maps as well.

Results: Significant spatial clusters of high values (hot spots) and low values (cold spots) of in-degree were identified. A cluster of high values was located in the central area of the province, and a cluster of low values involving municipalities of the Western zone was detected. Logistic regression demonstrated that a higher human population density per district was associated (odds ratio $=16.020,95 \%$ confidence interval: $1.692-151.682, \mathrm{p}=0.016$ ) with areas of high pork production.

Conclusion: Hot spot of swine production in Pinar del Río is associated with human densely populated districts, which may suppose a risk of spillover of pathogens able to infect animals and humans. These results can be considered in strategy planning in terms of pork production increases and improvements of sanitary, commercial, and economic policies by decision-makers.
\end{abstract}

Keywords: cluster, Getis-Ord, logistic regression, network analysis, swine.

\section{Introduction}

Pig rearing contributes decisively to the domestic economy of many families and national food security. It was an alternative for facing the economic constrictions. Since the last decade of the past century, a new strategy has been developed to stimulate pig rearing by private and cooperative sectors under a previous agreement with the state farming, which includes an improvement of sanitary measures and the veterinary control. The increases of swine population under the above conditions could also mean an increase of risk for human health since a higher animal-human health interface supposed an increased risk for human cases by zoonotic diseases.

Copyright: Fonseca, et al. This article is an open access article distributed under the terms of the Creative Commons Attribution 4.0 International License (http://creativecommons.org/licenses/ by/4.0/), which permits unrestricted use, distribution, and reproduction in any medium, provided you give appropriate credit to the original author(s) and the source, provide a link to the Creative Commons license, and indicate if changes were made. The Creative Commons Public Domain Dedication waiver (http:// creativecommons.org/ publicdomain/zero/1.0/) applies to the data made available in this article, unless otherwise stated.
This commercial agreement between the state swine enterprises and private producers, known as "swine agreements" (in Spanish "Convenios porcinos"), briefly consists in a sort of vertical integration, in which the state swine farms sell post-weaning animals to the other sectors with a partial support of feeding, considering the retail of animal at a market weight of approximately $90 \mathrm{~kg}$. This alternative allows sharing pig production costs by its decentralization while creates employment opportunities and economic benefits for many stakeholders. However, such production system increases pig movement across the territory and may entails an increased risk of animal disease spreading and even zoonoses [1].

The network analysis is a useful method to assess animal movements, and it has been widely applied in veterinary epidemiology and in many other fields as well [2]. Among other applications, spatial analyses have been used to visualize spatial patterns in data, aiming to explain the observed patterns [3].

A spatial relationship between human and domestic pig populations has been shown in the 
risk of disease transmission between animals and humans (zoonosis), such as salmonellosis, leptospirosis, brucellosis, influenza, and hepatitis E, among others [1,4-7], and also in the spread of animal diseases such as classical swine fever (CSF), which is the most important disease affecting the pig production in Cuba. The association between CSF occurrence and the ingoing contact chain in Pinar del Río province was demonstrated by the network analysis [8].

Combining network analysis with spatial cluster detection to identify areas with higher or lower importance according to the level of production or with high risk of occurrence of disease outbreaks has been established as an interesting approach for the implementation or improvement of prevention, control, and surveillance activities [9].

In addition, the spatial link of animal production with human population densities may allow identifying areas with a higher risk of zoonosis. Identification of geographical areas where swine introduction is either significantly higher or lower and their association with human population density can be useful for those specialists working in the fields of production and health, and for decision-makers as well, taking into account their sanitary and productive potential impact. Therefore, this problematic issue is approached in the present work.

\section{Materials and Methods}

\section{Ethical approval}

This article does not contain any studies (experiment) with human or animal subjects performed by any of the authors.

\section{Study area}

The western most province of Cuba, Pinar del Rio, was the study scenario. This province is divided into 11 municipalities comprising 97 districts, which are the smallest administrative division in Cuba. In this province, the districts have an average of $90.57 \mathrm{~km}^{2}$.

\section{Data sources}

Records of pig movements at the people's council (municipality subdivision in Cuba) level from July 2010 to December 2012 were kindly provided by the provincial Animal Health Department, the Local Veterinary Authority. The number of animals entering (in-degree) the different districts was obtained by performing a network analysis. The districts were considered as network nodes and the pig movements between them as edges. The in-degree might not be the more precise parameter for our objective, but it was used in this case because the information on the number of pigs sent for slaughter was lacking and an effective pig census by producers was not available. Thus, it was assumed a direct relationship between the in-degree of pigs in a territory and the swine population.

The data of human population by districts were obtained from the official statistical records [10]. They were used to calculate the human density per $\mathrm{km}^{2}$ by districts.

\section{Statistical analysis}

The in-degree parameter was calculated using the software R 3.1.3 [11]. The graphical representation of the network was carried out with Gephi 0.8.2 [12]. ArcGIS 10.2 [13] was used in the spatial analysis for detecting clusters of high and low swine in-degree by hot spot analysis (Getis-Ord Gi*); this tool identifies significant spatial clusters of high values (hot spot) and low values (cold spot). The fixed distance band was established in $40 \mathrm{~km}$, determined using Moran's index, and the Euclidean metric was used as distance method. For this study, true clusters were just considered when they were significant at least with $95 \%$ confidence.

A logistic regression was used for testing the association between clusters ( $>95 \%$ confidence) of swine in-degree and human population density. The dependent variable took value 1 for districts belonging to the cluster and 0 otherwise, and the human population density was analyzed as an independent variable (continuous variable) and calculated using the number of inhabitants divided by the area of each districts, this variable was standardized (i.e. subtracting by the mean and dividing by the standard deviation). The logistic regression was made using Epidat 4.2 [14].

The animal movement network and the detected clusters were visualized using ArcGIS 10.2 [13].

\section{Results and Discussion}

The yielded network of swine movements in the provinces where represented geographically, the number of pigs (in-degree) entering each district is shown in Figure-1.

The network analysis is a method applied to investigate live animal movements, and it is used each year by more and more researchers for several purposes, such as for example, for the support of disease control strategies and risk-based surveillance [15]. Within the veterinary epidemiology field, this method has been increasingly popular in the recent years [15-19]. This method can help to explore the potential of speed and range of spread of an infectious agent [17].

Significant spatial clusters of high values (hot spot) and low values (cold spot) of swine in-degree were identified (Figure-2). The significant cluster of high values was located on the central area of the province, where the provincial capital is also placed and, therefore, the largest human population density and commerce activity. The spatial analysis detected a swine in-degree hot spot of 29, 19, and 1 districts were significant for $90 \%, 95 \%$, and $99 \%$ confidence. Other cluster of low in-degree involving districts of the Western zone was detected; this area has a low human population density and a low economic activity in the province. This cold spot involved four districts significant for $90 \%$ confidence and one district for $95 \%$ confidence.

On the other hand, spatial analysis to detect either hot or cold spots of different events has been widely used. Getis-Ord Gi* can identify the locations 


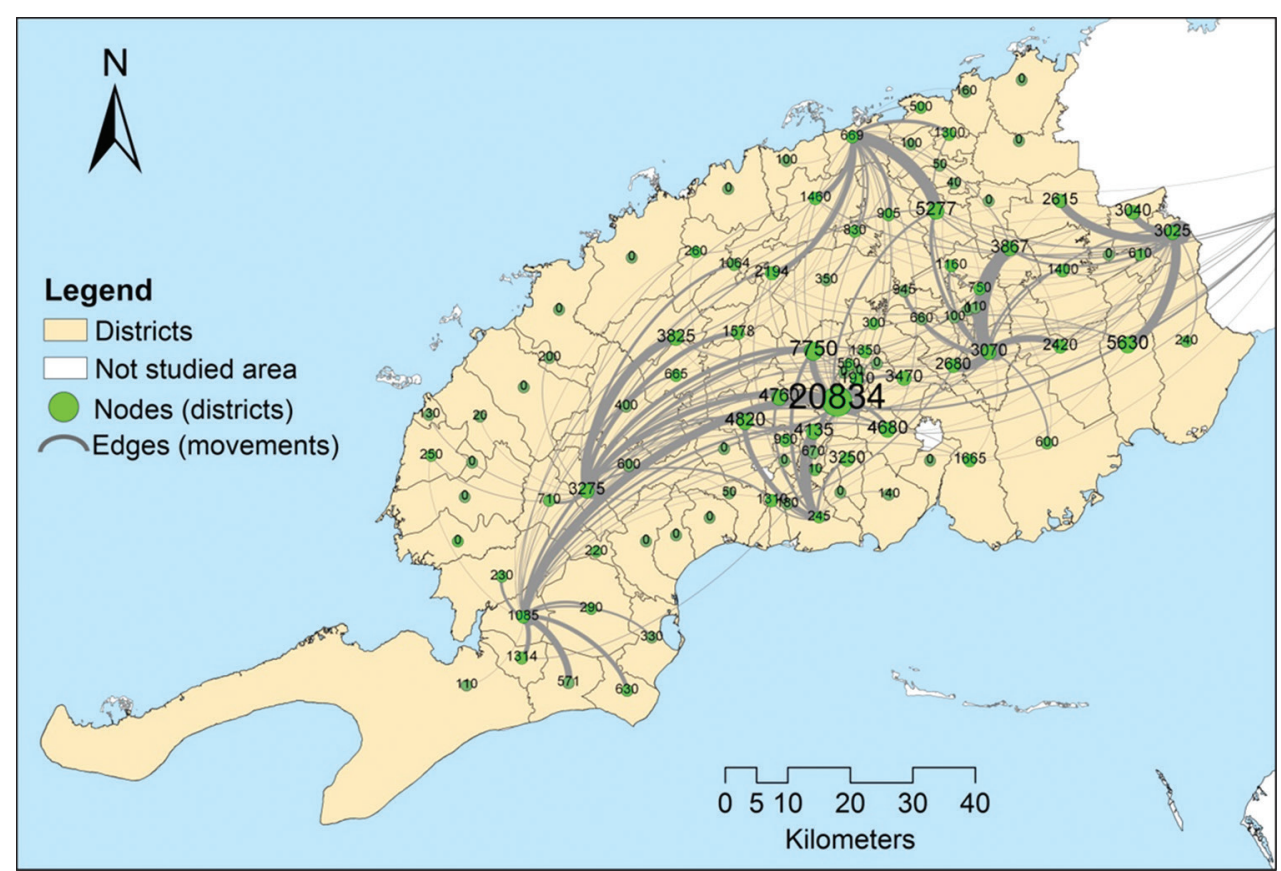

Figure-1: Spatial location of the pig movement network (numbers in green nodes represent the in-degree value).

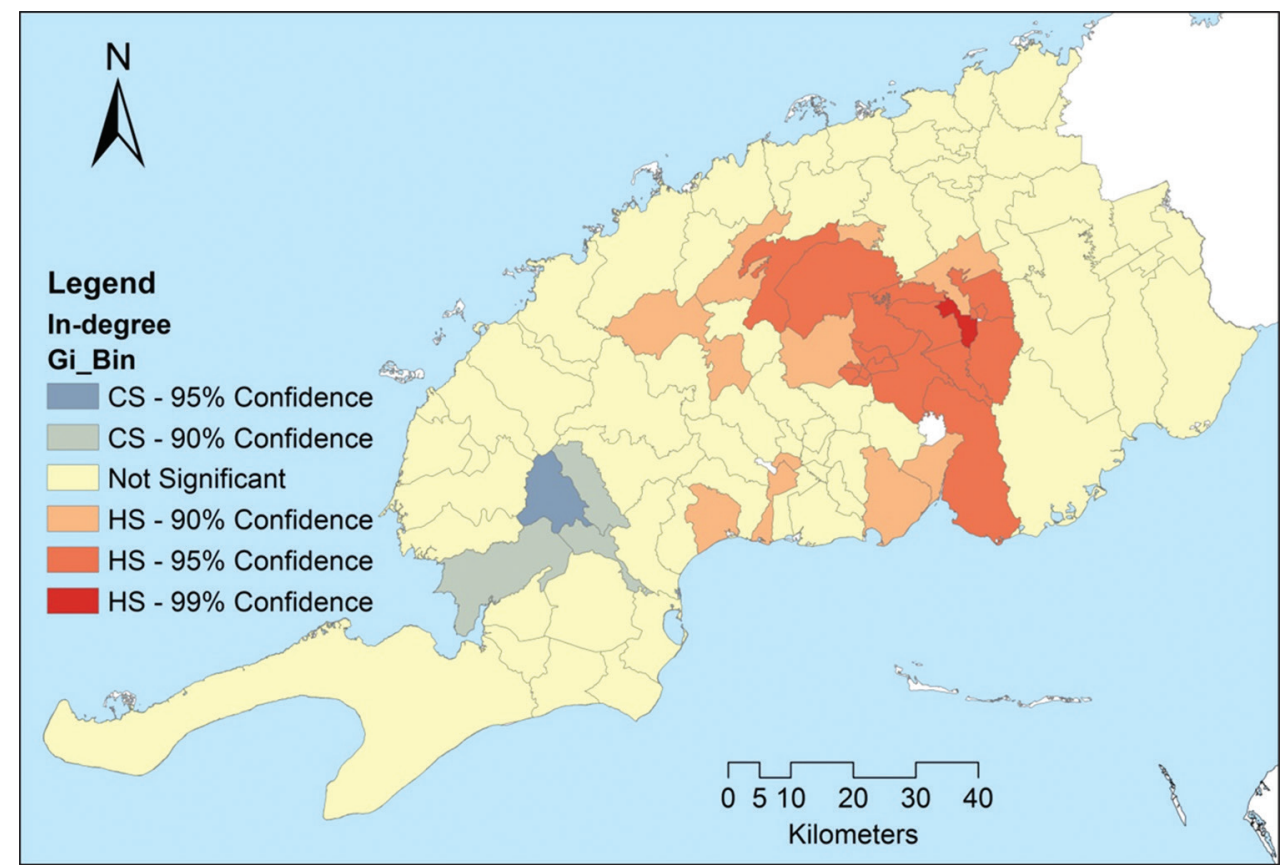

Figure-2: High and low swine in-degree spatial clusters (CS - Cold spot and HS - Hot spot).

of clusters of high and low values that are referred to as hotspots and cold spots, of respectively [20,21]. This technique has been used in epidemiology, criminology, sociology, etc. for detecting areas with high and low values of occurrence of certain events.

Spatial patterns of event distribution are widely divided into random, contagious, and regular patterns. There is special interest in clustering of events because it may help to identify a common environmental factor or source of exposure [22]. In this particular case, it was used to the detect clusters of districts with high and low values of in-degree of pigs, these clusters of high and low in-degree represent areas of high and low pig production.
Other authors have combined network and spatial analysis with the aim of investigating the importance of network and spatial location in equine influenza spread in Australia [23] and also describing the equine influenza spread between horse premises, differentiating spread occurring through a known contact network from secondary local spatial spread [24]. It has also been used to identify temporal-spatial clusters of agricultural operations at high risk for the introduction and spread of diseases through the shipment of live pigs in the Spanish province of Salamanca [9].

Taking into account the spatial coincidence of the swine in-degree hot spot and districts with high human population density and, on the other hand, 
a priori knowledge about the social tradition of pig breeding and its economic importance for the people, it was made the test for the spatial relationship between swine in-degree hot spot detected and human population density.

It was shown that a higher human population density per districts is associated (odds ratio $=16.020$, 95\% confidence interval: 1.692-151.682, $\mathrm{p}=0.016$ ) with the areas of high swine production (Table-1), and the probability of belonging to the cluster of high swine in-degree and the human population density was represented graphically (Figure-3).

As it is shown in Table-1 and Figure-3, the human population density was associated with the pig production activity in Pinar del Río province. In Cuba, backyard pig rearing and pig contracts, both by the same producers in very close facilities, is very common because the pork and its by-products are highly demanded and results in high incomes; it is why the most densely populated districts are those where the pig production is concentrated.

Livestock production is frequently concentrated near and around cities to meet the food needs of human settlements. These are the cases of cow milk and poultry egg production belonging to producers of medium and low income [25].

In Cuba, pork is an important source of animal protein in the people diet, and the retail network is very complex and extensive among informal sellers and also the official market. Detection of areas with high or low importance from the productive point of view could help to improve the best logistic plans as well as epidemiologic surveillance. The hot spot zone should be considered a place in the province with the highest probability of entry of animal diseases and zoonosis through live animal movements. Movement of animals is considered the main risk factor for the introduction of many infectious diseases [26,27].

Veterinary medicine plays an essential role in protecting and promoting public health, especially in the prevention and control of zoonotic diseases [4]. Zoonotic disease agents account for approximately $75 \%$ of emerging human pathogens and for over half of known human pathogens [28].

Some of the diseases affecting livestock are zoonotic, and transmission can occur through direct contacts, indirect environmental contacts, or through food [29]. A lot of zoonotic diseases are well known to be a public health concern, for example, Salmonella is one of the most common and serious zoonotic foodborne pathogenic bacterium worldwide [4]; it is also widely recognized that the influenza virus has the ability to jump the species barrier and infect humans [6]; leptospirosis is a potentially fatal zoonosis occurring in many mammalian species, including humans, and maintenance of leptospires in the natural environment is largely determined by the ability of the pathogenic leptospires to adapt to a large number of wild and domestic animals that serve as reservoir host(s) including pigs [5]; brucellosis and leptospirosis, both of which are zoonoses and whose mechanisms of disease between human and non-human populations have to be considered. An important factor that determines the occurrence of such occupationally acquired zoonosis (in veterinarians, abattoir workers and farmers) is the amount of disease in domestic animals [1]. Veterinary and public health

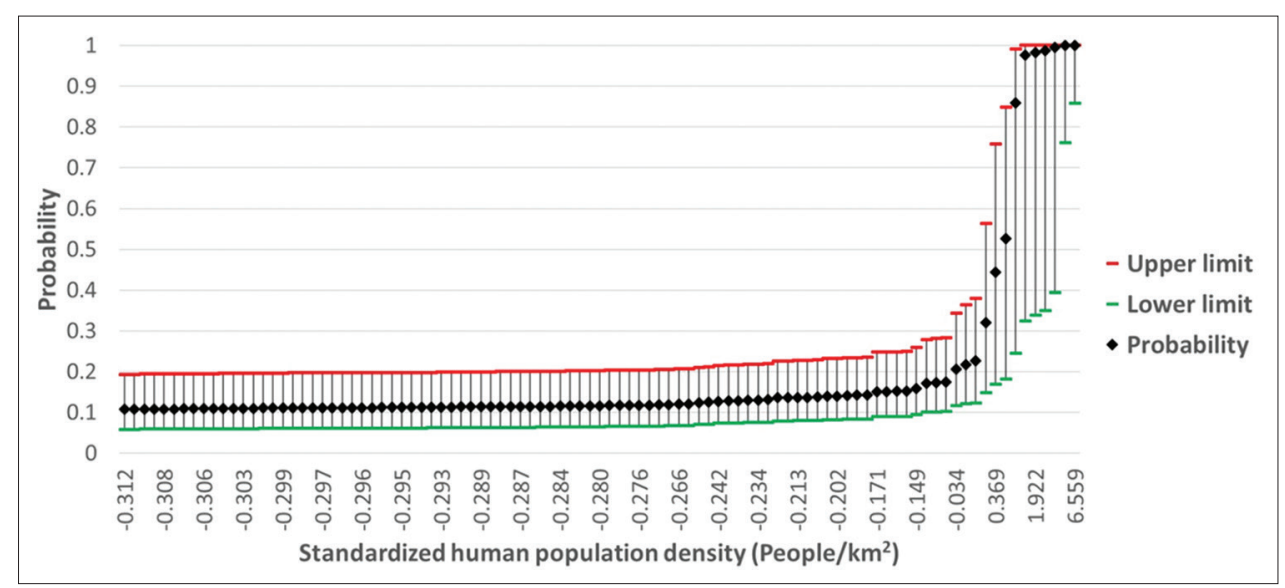

Figure-3: Association between high swine in-degree area and human population density.

Table-1: Output of logistic regression model analyzing associations between hot spot of swine in-degree area (95\% confidence) and human population density.

\begin{tabular}{|c|c|c|c|c|c|c|c|c|}
\hline \multirow[t]{2}{*}{ Variable } & \multirow[t]{2}{*}{ B } & \multirow[t]{2}{*}{ SE } & \multirow[t]{2}{*}{ Wald } & \multirow[t]{2}{*}{ df } & \multirow[t]{2}{*}{ p value } & \multirow[t]{2}{*}{ OR } & \multicolumn{2}{|c|}{$95 \% \mathrm{CI}$} \\
\hline & & & & & & & Lower & Upper \\
\hline $\begin{array}{l}\text { Standardized human population density } \\
\text { Constant }\end{array}$ & $\begin{array}{c}2.774 \\
-1.249\end{array}$ & $\begin{array}{l}1.147 \\
0.370\end{array}$ & $\begin{array}{c}5.849 \\
11.383\end{array}$ & $\begin{array}{l}1 \\
1\end{array}$ & $\begin{array}{l}0.016 \\
0.001\end{array}$ & $\begin{array}{c}16.020 \\
0.287\end{array}$ & 1.692 & 151.682 \\
\hline
\end{tabular}

$\mathrm{OR}=$ Odds ratio, $\mathrm{CI}=$ Confidence interval, $\mathrm{SE}=$ Standard error 
authorities must pay special attention to clustered areas of pig in-degree because could be a high interaction between pigs and humans that could increase the risk of cases of zoonosis.

In Pinar del Río, the high human population density is associated with the high pork production because it is a common activity assumed by many people because of its economic benefits in the present economic context. The possibilities of a higher interaction between humans and pigs in these areas may suppose a higher risk of occurrence and transmission of zoonosis that should be investigated. Pigs have long been known to serve as reservoirs for zoonotic pathogens, some of them have become well-established in swine populations, impairing health and economic burdens [7]. Frequently changing husbandry practices and environmental factors (e.g. large scale domestic animal production, urbanization, interaction between wild and domestic animal populations with humans, population increases, etc.) may predispose humans and pigs to pathogens common to other species or may allow for the adaptation of these organisms to humans or swine [7].

These results offer insights for a better understanding of the risk of zoonosis and of those areas deserving a deeper intersectoral collaboration for surveillance and management of the associated risks. It could reveal spatial patterns of zoonosis infection and risk factors and could contribute to develop surveillance activities and control measures in animal and human populations.

Furthermore, the spatial association between high pig and human population densities could be as well a risk factor for the occurrence of diseases in the pig. In Cuba, CSF is endemic [30], this is one of the most devastating diseases in swine, concerning both economic and sanitary issues [31]. In a previous study, in which identification of risk factors contributing to CSF occurrence in Bulgaria was one of the objective, human demography variables, such as population by municipality, place of residence (urban, rural) and gender, were analyzed. Socioeconomic factors, such as household consumption and overall poverty including level of poverty, were also analyzed. This study showed interesting results identifying total urban population, among others, as a risk factor for CSF occurrence [32].

Moreover, socioeconomic and cultural factors are recognized as risk factors for the spread and maintenance of infectious disease like African swine fever (ASF). Those factors are very difficult to change because are part of the human behavior. Only the strict application of law, along with the use of new techniques to facilitate disease management, can help fight against ASF in these areas [33].

Those areas with the highest proportion of exposed humans become candidates for greater demands for biosecurity and its control. Further research works are needed to determine the prevalence and incidence of important animal diseases and zoonoses in those areas and for identification of risk factors. Meanwhile, some actions can be implemented to reduce the potential risk of disease transmission, for example by (i) increasing the sanitary education of the population in general, but specifically of the workers having contact with swine; (ii) reinforcing the biosecurity level of the swine farms; (iii) giving special attention to the treatment of the swine farming wastewater; (iv) strengthening the epidemiological surveillance for swine and humans; (v) intensifying the control of animal movement; among others measures.

Prevention and early control of disease outbreaks could be the key to reducing the impact of epidemics and potential pandemics, especially in less developed countries (One Health proof of concept: Bringing a transdisciplinary approach to surveillance for zoonotic viruses at the human-wild animal interface, 2016).

\section{Conclusions}

Hot spot of swine production in Pinar del Río is associated with human densely populated districts, which may suppose a risk of spillover of pathogens able to infect animals and humans. Demographic and socioeconomic factors could be associated with outbreaks of infectious diseases in swine population. Policy makers must consider these results for planning strategies in terms of reforming the increasing swine production in areas with high density of human population, commercial and economic activities, and also of improving sanitary measures such as disease surveillance and control strategies.

\section{Authors' Contributions}

OFonseca: Data collecting, analyses and graphic representation of results, manuscript writing. KRS: Manuscript reviewing, reference search, study conduction, statistical assistance, research advisor. PA: Manuscript reviewing and reference search. JA: Data collecting, manuscript reviewing, reference search. MAA: Manuscript reviewing. OF: Manuscript reviewing. YC: Data collecting and analyses. DNM: Data collecting and analyses. MIP: Manuscript reviewing, reference search, study conduction, epidemiological analysis assistance. All authors read and approved the final manuscript.

\section{Acknowledgments}

The authors recognize the contribution of the DSA for their advices for carrying out this study. This work is part of the objectives of the Project 203/13 "Applied statistical modeling to assess the sanitary and economic impact of prevention and control programs in animal production. Case study: Avian influenza and CSF" developed within the cooperation of OIE Collaborating Center for Disaster Risk Reduction in Animal Health (National Center for Animal and Plant Health) and the UFRPE (Federal Rural University of Pernambuco), supported by the International Cooperation Program CAPES/MES 
(Brazilian Federal Agency for Support and Evaluation of Graduate Education/Cuban Ministry of Higher Education).

\section{Competing Interests} interests.

The authors declare that they have no competing

\section{References}

1. Thrusfield M. Veterinary Epidemiology. Canada: Elsevier; 2013.

2. Puerta JL. Network analysis and medicine: A new perspective. Med Clin (Barc) 2013;140:273-7.

3. Pfeiffer D, Robinson T, Stevenson M, Stevens K, Rogers D, Clements A, et al. Spatial Analysis in Epidemiology. New York, Italia: Oxford University Press, FAO; 2008.

4. Benschop J. Epidemiological Investigations of Surveillance Strategies of Zoonotic Salmonella: A Dissertation Presented in Partial Fulfilment of the Requirements for the Degree of Doctor of Philosophy at Massey University; 2009.

5. Gautam R, Guptill LF, Wu CC, Potter A, Moore GE. Spatial and spatio-temporal clustering of overall and serovar-specific Leptospira microscopic agglutination test (MAT) seropositivity among dogs in the United States from 2000 through 2007. Prev Vet Med 2010;96:122-31.

6. De Nardi M, Hill A, Dobschuetz S, Munoz O, Kosmider R, Dewe $\mathrm{T}$, et al. Development of a Risk Assessment Methodological Framework for Potentially Pandemic Influenza Strains (FLURISK). Vol. 11. EFSA Supporting Publications 2014; 11(5)

7. Uddin Khan S, Atanasova KR, Krueger WS, Ramirez A, Gray GC. Epidemiology, geographical distribution, and economic consequences of swine zoonoses: A narrative review. Emerg Microbes Infect 2013;2:e92.

8. Fonseca O. Caracterización Espaciotemporal y Factores de Riesgo del Comportamiento Endémico de la Peste Porcina Clásica en Cuba: Thesis Submitted for Doctor of Philosophy. Cuba: Agricultural University of Havana; 2016.

9. Martínez-López B, Perez AM, Sánchez-Vizcaíno JM. Combined application of social network and cluster detection analyses for temporal-spatial characterization of animal movements in Salamanca, Spain. Prev Vet Med 2009;91:29-38.

10. ONEI. Oficina Nacional de Estadística e Información. República de Cuba; 2015. Available from: http://www.one. cu. Accessed on 10-12-2015.

11. R Development CoreTeam. R: A Language and Environment for Statistical Computing. R Foundation for Statistical Computing, Vienna, Austria; 2012. Available from: http:// www.r-project.org. Accessed on 06-15-2015.

12. Gephi Consortium. Gephi. Computer Program (Version 082 Beta). Vol. 14; 2014. Available from: https://www. gephi.org. Accessed on 03-21-2015.

13. ESRI. ArcGIS E. Release 10.2. Redlands, CA: ESRI; 2011.

14. Vidal XH, Barbeito GN, Pérez MI, Lengua ÓJ, Fernández EV, Hernández RM, et al. Epidat: Programa Para Análisis Epidemiológico de Datos. Consellería de Sanidade. $42^{\text {nd }}$ ed. España, Colombia: Organización Panamericana de la Salud (OPS-OMS); Universidad CES, Xunta de Galicia; 2016.

15. Nöremark M, Hakansson N, Lewerin SS, Lindberg A, Jonsson A. Network analysis of cattle and pig movements in Sweden: Measures relevant for disease control and risk based surveillance. Prev Vet Med 2011;99:78-90.

16. Molia S, Boly IA, Duboz R, Coulibaly B, Guitian J, Grosbois $\mathrm{V}$, et al. Live bird markets characterization and trading network analysis in Mali: Implications for the surveillance and control of avian influenza and Newcastle disease. Acta Trop 2016;155:77-88.

17. Smith RP, Cook AJ, Christley RM. Descriptive and social network analysis of pig transport data recorded by quality assured pig farms in the UK. Prev Vet Med 2013;108:167-77.

18. Dorjee S, Revie CW, Poljak Z, McNab WB, Sanchez J. Network analysis of swine shipments in Ontario, Canada, to support disease spread modelling and risk-based disease management. Prev Vet Med 2013;112:118-27.

19. Frössling J, Ohlson A, Björkman C, Håkansson N, Nöremark M. Application of network analysis parameters in risk-based surveillance-examples based on cattle trade data and bovine infections in Sweden. Prev Vet Med 2012;105:202-8.

20. Harun SM, Ogneva-Himmelberger Y. Distribution of industrial farms in the United States and socioeconomic, health, and environmental characteristics of counties. Geogr J 2013;2013:1-12.

21. Smith C, Skelly C, Kung N, Roberts B, Field H. Flyingfox species density - A spatial risk factor for Hendra virus infection in horses in eastern Australia. PLoS One 2014;9:e99965.

22. Premashthira S, Salman MD, Hill AE, Reich RM, Wagner BA. Epidemiological simulation modeling and spatial analysis for foot-and-mouth disease control strategies: A comprehensive review. Anim Health Res Rev 2011;12:225-34.

23. Firestone SM, Ward MP, Christley RM, Dhand NK. The importance of location in contact networks: Describing early epidemic spread using spatial social network analysis. Prev Vet Med 2011;102:185-95.

24. Firestone SM, Christley RM, Ward MP, Dhand NK. Adding the spatial dimension to the social network analysis of an epidemic: Investigation of the 2007 outbreak of equine influenza in Australia. Prev Vet Med 2012;106:123-35.

25. Ellis F, Sumberg J. Food production, urban areas and policy responses. World Dev 1998;26:213-25.

26. Martínez-López B, Perez AM, De la Torre A, Rodriguez JM. Quantitative risk assessment of foot-and-mouth disease introduction into Spain via importation of live animals. Prev Vet Med 2008;86:43-56.

27. Bigras-Poulin M, Thompson RA, Chriel M, Mortensen S, Greiner M. Network analysis of Danish cattle industry trade patterns as an evaluation of risk potential for disease spread. Prev Vet Med 2006;76:11-39.

28. Taylor LH, Latham SM, Woolhouse ME. Risk factors for human disease emergence. Philos Trans R Soc Lond B Biol Sci 2001;356:983-9.

29. Noremark M. Infection through the Farm Gate: Studies on Movements of Livestock and On-Farm Biosecurity. Uppsala: Department of Clinical Sciences, Swedish University of Agricultural Sciences; 2010.

30. Postel A, Schmeiser S, Perera CL, Rodríguez LJ, FriasLepoureau MT, Becher P. Classical swine fever virus isolates from Cuba form a new subgenotype 1.4. Vet Microbiol 2013;161:334-8.

31. Moennig V, Floegel-Niesmann G, Greiser-Wilke I. Clinical signs and epidemiology of classical swine fever: A review of new knowledge. Vet J 2003;165:11-20.

32. Martínez-López B, Alexandrov T, Mur L, SánchezVizcaíno F, Sánchez-Vizcaíno JM. Evaluation of the spatial patterns and risk factors, including backyard pigs, for classical swine fever occurrence in Bulgaria using a Bayesian model. Geospat Health 2014;8:489-501.

33. Mur Gil L. Nuevas Estrategias Para la Prevención y Control de la Peste Porcina Africana. España: Universidad Complutense de Madrid; 2015. 